\title{
Intensification of Heterogeneous Photocatalytic Reactions Without Efficiency Losses: The Importance of Surface Catalysis
}

\author{
Jonathan Z. Bloh ${ }^{1}$ D
}

Received: 5 November 2020 / Accepted: 16 February 2021 / Published online: 9 March 2021

(c) The Author(s) 2021

\begin{abstract}
Advances in LED and photoreactor technology have brought semiconductor photocatalysis to the verge of feasibility of industrial application for the synthesis of value-added chemicals. However, the often observed efficiency losses under intensified illumination conditions still present a great challenge. This perspective discusses the origin of these efficiency losses and what needs to be done to prevent or counteract it and pave the way for efficient, intensified heterogeneous photocatalytic processes. The role of surface catalysis is particularly highlighted as one of the rate-limiting steps.
\end{abstract}

\section{Graphic Abstract}

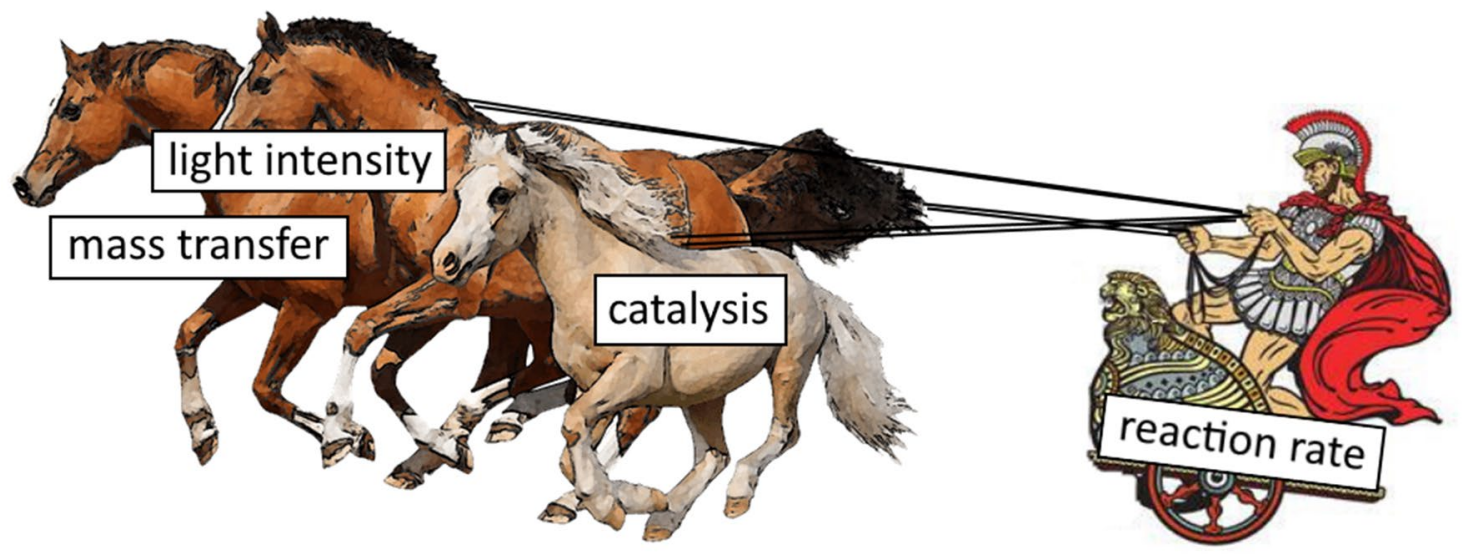

Keywords Semiconductor photocatalysis $\cdot$ High light intensity $\cdot$ Rate acceleration $\cdot$ Industrial implementation $\cdot$ Catalytic efficiency

\section{Introduction}

The importance of photocatalysis both in fundamental and applied science has rapidly increased in the last decades [1]. Intensive research has brought forth potential application in the treatment of wastewater [2] or air pollution [3], self-cleaning/disinfecting surfaces [4, 5] and

Jonathan Z. Bloh

jonathan.bloh@dechema.de

1 DECHEMA-Forschungsinstitut, Theodor-Heuss-Allee 25, 60486 Frankfurt am Main, Germany the generation of sustainable fuels from sunlight $[6,7]$. In recent years, also the application in organic synthesis has attracted increasing attention [8-13]. Due to their highenergy states and radical chemistry [14] photocatalytic reactions often allow completely new reaction pathways with potential shortcuts in many production routes. Coupled with the fact that they are typically operated under mild conditions and that the required photon energy can be generated carbon neutral using renewable energy sources, photocatalysis has great potential as a powerful tool in green chemistry $[15,16]$. In contrast to the very popular photoredox chemistry which uses molecular photocatalysts 
such as homogeneously dissolved dye molecules or complexes $[13,17]$, heterogeneous photocatalysis using semiconductor (nano)particles promises advantages in industrial implementation such as cheaper and more durable catalysts as well as easier re-use and separation from the reaction medium.

However, so far the vast majority of heterogeneous photocatalytic reactions have been performed under conditions yielding only slow reaction rates. The resulting reaction rates of only few $\mathrm{mM}$ per hour at best are rather low in comparison with traditional chemical syntheses and therefore render these reactions unattractive if alternatives are available. If heterogeneous photocatalytic reactions are to be industrially implemented, the reaction rates need to be increased to allow for molar concentrations of products to be generated within few hours. To account for losses resulting from imperfect quantum yield, this in turn requires specific photon fluxes in the range of $\mathrm{M} \mathrm{h}^{-1}$ equaling radiant flux densities of at least $100 \mathrm{~W} \mathrm{~L}^{-1}$.

So far, this intensification has been hampered by two effects. The first one is the simple unavailability of light sources strong enough to generate a sufficiently high photon flux, apart from using lasers focused on very small volumes [18]. This is starting to be no longer the case with the advent of highly efficient and affordable high-power LEDs which enable specific light intensities 1-2 orders of magnitude higher than traditionally used light sources such as xenon or mercury vapor lamps $[19,20]$. By using intensified reactor concepts such as photomicroreactors [21-23] falling-film [24] or other thin-film reactors [25] the specific light intensity can be further increased by several orders of magnitude, albeit only with small reaction volumes [26, 27]. Alternatively, internal illumination techniques also enable intensified light intensity at larger scales [28].

The second challenge for intensification is the often observed non-linear response of the reaction rate at higher light intensities. Typically, at low light intensity a linear response of the reaction rate with the light intensity is initially observed [29]. However, as shown exemplary in Fig. 1, after reaching a certain critical light intensity, the reaction rate stops following this trend and gradually shows a lower response, resulting in non-linear behavior at high light intensity [20,30-34]. This critical point is typically reached even in traditional setups featuring only moderate light intensity. Although this has in rare cases been reported for molecular photocatalysts at very high light intensity [18] this phenomenon appears to be almost exclusively related to heterogeneous photocatalysis. While it is still possible to accelerate the reactions using higher light intensity, this quickly becomes inefficient due to the increasingly diminishing returns. Also, the associated drop in photonic efficiency greatly increases the specific energy consumption and may thereby make the process uneconomical.

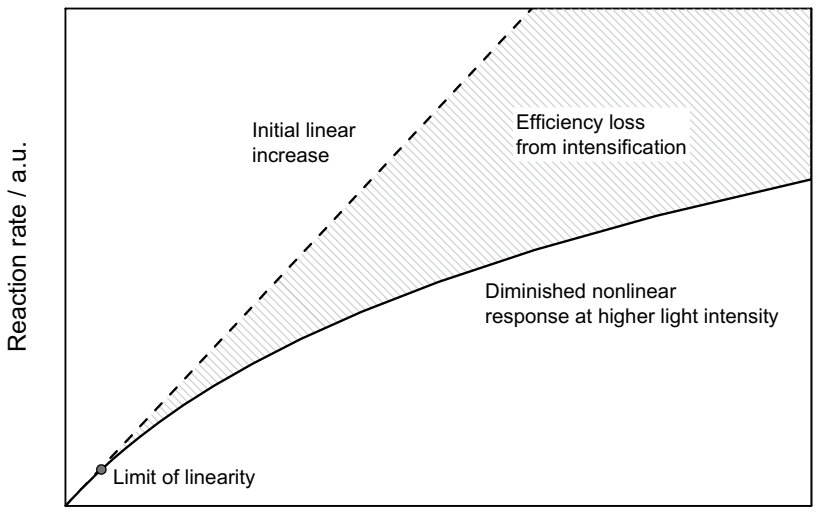

Light intensity / a.u.

Fig. 1 The typically observed reaction rate response to light intensity for heterogeneous photocatalytic reactions

Is therefore the intensification of heterogeneous photocatalytic reactions only possible with dramatic losses in efficiency, rendering the processes unattractive for industrial implementation? Or are there ways to prevent this from happening and to combine high efficiency with fast reactions? To answer these questions, the origin of this efficiency loss should first be discussed.

\section{The Origin of Efficiency Loss at High Light Intensity}

So far, efficiency losses in heterogeneous photocatalysis have often been treated as a problem of the separation of the photo-generated charges and preventing their recombination. The more charges are generated, the higher the chances of recombination become, hence the drop in efficiency at higher light intensity [35]. Since recombination is the terminal loss process in photocatalysis, this statement must be true [36]. However, the underlying mechanisms and reasons for recombination may be misinterpreted.

Recombination is for instance attributed to bulk effects of the semiconductor material such as defects acting as socalled recombination centers [37]. Consequently, many of the charge carriers are thought to be lost before they even reach the surface of the catalyst. As a potential remedy to this problem, heterojunctions became quite popular in order to increase the driving force for charge separation inside the photocatalyst, similar to the p-n-junction found in photovoltaic devices [38]. However, there are several hints pointing toward the photophysical properties of the photoabsorber not being the actual cause of recombination.

For a given photocatalyst, different reactions are often reported to proceed with wildly varying quantum efficiency even under otherwise similar conditions. This is a strong counterindication for the bulk of the catalyst being involved 
in the responsible loss process since it has no direct contact with the reactant. For instance, the often employed commercial catalyst Aeroxide P25 (Evonik) exhibits an extremely high apparent quantum yield for nitrobenzene reduction even at high light intensity, proving that the material itself is capable of extremely efficient conversions [39]. Lower observed efficiencies in other reactions with the same catalyst are therefore unlikely to be caused by the photophysical properties of the photocatalyst [40]. The source of the inefficiency is more likely found in the nature of the reaction itself, i.e. the interaction of target substrate and photocatalyst. Consequently, in these cases recombination appears to predominantly happen after the charges have reached the surface due to insufficiently fast charge transfer to the target substrates.

The comparison to photovoltaics (PV) is also interesting. For PV, increasing the light intensity typically produces a linear current increase while at the same time, the open circuit voltage increases. As a result, as long as the cell series resistance is kept in check, PV efficiency actually increases with higher light intensity. There are of course fundamental differences between PV and photocatalysis, the most prominent one being the direct interface of the semiconductor with the liquid or gaseous reaction medium. Consequently, this also hints at the interface being the source of the efficiency drop at higher light intensity.

Both of these aspects point towards the bulk material of the semiconducting photocatalyst being only of minor importance in the recombination (at least for materials with proven high efficiency in some reactions). Most of the charges appear to be lost on the surface of the photocatalyst particles. Here, they recombine while waiting to be transferred to the target substrate; it is this fundamental reaction step that appears to often be the limiting factor. However, this charge transfer reaction is not governed by the photophysical properties of the material but by mass transfer and catalysis.

When the light intensity is increased, the flux of charges that need to be transferred at the photocatalyst's surface also increases. However, if mass transfer and catalytic turnover frequencies remain unchanged at the same time, they increasingly become the limiting factor. This shift from photon limitation at low and kinetic limitation at high light intensity is the origin of the observed photon efficiency loss at higher light intensity. This effect was also recently predicted by kinetic modeling [41].

\section{Catalysis in Photocatalysis}

Fundamentally, heterogeneous photocatalysis follows the same basic reaction steps as conventional (thermal) heterogeneous catalysis with the addition of photon absorption and charge migration to the surface. The elementary reaction steps for a successful heterogeneous photocatalytic model reaction $\mathrm{A}+\mathrm{B}->\mathrm{C}^{\bullet-}+\mathrm{D}^{\bullet+}$ are illustrated in Fig. 2. Note that for the sake of simplicity only the slower of the two separately occurring half-reactions is considered $\left(\mathrm{A} \longrightarrow \mathrm{C}^{\bullet-}\right.$ in this case). The first step (I) is the absorption of photons, generation of charge carriers and their migration to the surface where they are trapped, forming excited (in this case reduced) active sites $\left(\mathrm{S}^{*}\right)$. Once the charges have reached the surface, the following reaction steps are akin to heterogeneous catalysis. The target substrate (A) is adsorbed at this active site (II), which may happen either before or after the first step. The excited active site then reacts with the adsorbed substrate, transferring the photogenerated charge and forming the product $\left(\mathrm{C}^{\bullet-}\right)$ (III). Usually, it is one of these first three reaction steps that is rate-limiting, depending on the overall reaction conditions. Afterwards, the product is desorbed from the surface (IV), although depending on the nature of the reaction, subsequent reaction steps may happen even before desorption.

At high light intensities where the photocatalyst begins to be saturated with photons and active sites become permanently excited, the first reaction step can be considered instantaneous. At this point the catalyst starts to behave like a traditional heterogeneous catalyst, since the remaining reaction steps are essentially the same. The onset of this is often apparent far before the majority of photocatalyst is saturated. Due to the exponential decay of light intensity inside the reactor, it is much easier to achieve photon saturation in the bright spots nearest to the light source than farther away in the bulk of the reactor [41]. Once photon saturation begins to manifest even in parts of the reactor, the efficiency can be improved by the same means known from classical heterogeneous catalysis.

While temperature is absolutely critical in conventional thermal catalysis it is typically not studied in detail in

General reaction scheme of a model reaction: $\quad A+B \stackrel{P C, h v}{\longrightarrow} C^{\cdot-}+D^{*+}$

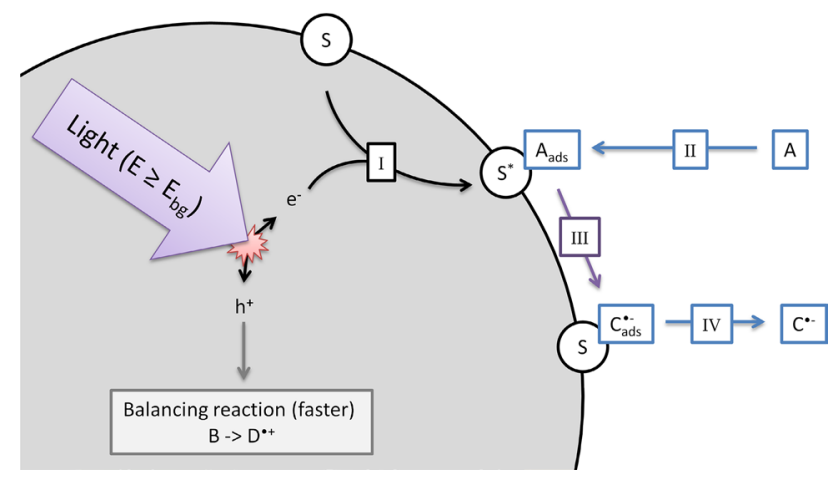

Fig. 2 Schematic illustration of the elementary reaction steps (I-IV) for a model reaction in heterogeneous photocatalysis 
photocatalysis. The rationale behind this seems to be that the reaction is initiated by the massive energy provided by the photons, so room temperature is sufficient to drive the reactions [29, 42-44]. Yet, there are many publications which clearly show a temperature dependence of the photocatalytic reactions and use the Arrhenius law to calculate apparent activation energies $\left(\mathrm{E}_{\mathrm{A}}\right)$ of 5 to $28 \mathrm{~kJ} \mathrm{~mol}^{-1}$ [45-49].

Consequently, the reaction rates can be increased with higher temperatures. For instance, the photocatalytic oxidation rate of ethylene was found to more than double when the temperature was increased from 60 to $160{ }^{\circ} \mathrm{C}$ [50]. Recently, it has also been reported that the photocatalytic water splitting reaction greatly benefits from elevated temperatures, reaching astonishing quantum yields of more than $80 \%$ at $270{ }^{\circ} \mathrm{C}[51]$.

Even mildly heating up the reaction medium can have a significant effect. For instance the photocatalytic reduction of nitrobenzene was reported about $50 \%$ more efficient at $65^{\circ} \mathrm{C}$ versus $15^{\circ} \mathrm{C}$ [39]. In the same temperature range, the photocatalytic reduction rate of molecular oxygen increases by the factor of 3 [40]. The photocatalytic chlorine oxidation showed a very pronounced temperature effect in one study, with almost sevenfold as high reaction rates at $120^{\circ} \mathrm{C}$ compared to $20^{\circ} \mathrm{C}$ [25]. However, another study on the same reaction reported a much weaker temperature effect with only about $150 \%$ activity increase in the same temperature range [52].

At first glance it seems odd that some studies observe a dependence on the temperature while others do not and sometimes even for the same reaction, seemingly conflicting results are reported. However, this can easily be explained by the simple fact that the temperature dependence only really becomes apparent at high light intensity when the photocatalyst switches from photon to kinetic limitation. At lower light intensity the reaction is mostly photon-limited, masking the temperature dependence. In those cases, it cannot be directly observed, i.e. only intensified conditions require higher temperatures (or other means to increase the catalyst's efficiency). The true unmitigated activation energy can therefore only be observed under conditions of complete photon saturation [41].

This is illustrated in Fig. 3 on the basis of an exemplary calculation according to a previously published holistic model [41]. Here it is evident that the relative reaction rate increase when going from 20 to $80^{\circ} \mathrm{C}$ is strongly dependent on the photon flux. The modeled photon fluxes correspond approximately to 5,50 and $500 \mathrm{~W} \mathrm{~L}^{-1}$, representing scenarios of mild, strong and very strong light intensity. This example nicely shows that at low or mild light intensity, the temperature effect is strongly diminished or may even be completely absent.

Obviously, increasing the reaction temperature in order to improve the catalytic efficiency also has downsides and

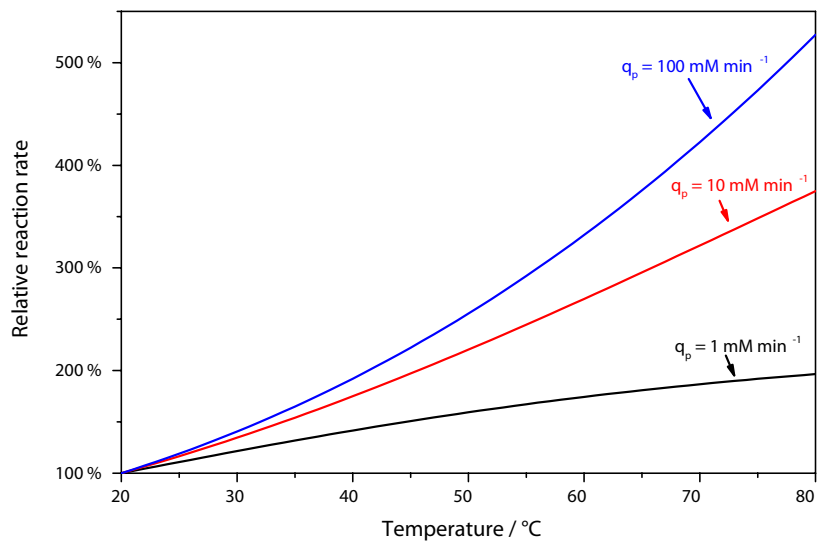

Fig. 3 Calculated reaction rates in dependence of the temperature for different photon fluxes $\left(\mathrm{q}_{\mathrm{p}}\right)$ according to a previously published model, normalized to the respective reaction rate at $20^{\circ} \mathrm{C}$. Model parameters: $\alpha=5 \mathrm{~L} \mathrm{~g}^{-1}, \mathrm{~A}=200 \mathrm{~mol} \mathrm{~g}^{-1} \mathrm{~min}^{-1}, \mathrm{E}_{\mathrm{A}}=30 \mathrm{~kJ} \mathrm{~mol}^{-1}$, $\mathrm{k}_{\mathrm{R}}=0.5 \mathrm{mM} \mathrm{min}^{-1}, \mathrm{c}_{0}=2.5 \mathrm{~g} \mathrm{~L}^{-1}, \phi=0.5$

limits. Some reaction steps such as adsorption or desorption may be negatively affected by higher temperatures and become rate limiting. Also, for exothermic reactions increasing the temperature may shift the thermodynamic equilibrium away from the product side and thereby limit the maximum conversion. At very high temperatures above $300{ }^{\circ} \mathrm{C}$, phonon-mediated recombination may also become a problem [50]. The possible temperatures are also limited by the boiling point of the employed solvent, unless also working at high pressure which would dramatically increase the complexity and costs of the employed equipment.

However, mild temperature increases up to about $80^{\circ} \mathrm{C}$ should not have these negative impacts while already contributing significantly towards higher reactivity and therefore present a valuable contribution to more efficient reactions. This also goes well with the fact that using highly intensified illumination conditions is usually accompanied by significant heat dissipation, so external heating may not even be required.

Another important aspect in conventional catalysis is the surface area of the catalyst material. Usually the available surface area correlates with the number of active sites and thereby determines the maximum possible reaction rate the catalyst [53]. However, this is not so clear in photocatalysis. In many studies, no clear trend between surface area and reaction rate can be observed [54]. There is considerable experimental difficulty in preparing truly comparable catalyst materials which only differ in their available surface area. Often this is attempted by using different calcinations temperatures or completely different synthesis methods but this also means that the resulting materials may have different crystallinity, facet distribution and defects which may impact upon their photophysical and catalytic properties [55]. Moreover, changing the catalyst shape and size may 
also alter its scattering properties, thereby influencing the light distribution in the reaction vessel [56].

Of those studies which report a correlation between surface area and reaction rate, they typically observe a saturation or plateau effect, i.e., after a certain surface area has been achieved, further improvements only show a lower or no effect at all [57-59]. This is readily explained by the fact that if very small surface area materials are used, the photocatalyst is already kinetically limited even at low light intensity so improving the surface area directly impacts upon the reaction rate. Once the surface area is sufficiently high for the applied conditions, gradually photon limitation takes over and the surface area does not matter as much anymore. According to this theory, this inflection point should shift to higher surface areas when the light intensity is increased, as illustrated in Fig. 4. In fact, in a comparison between the high surface area catalyst Hombikat UV100 and low surface area P25, it was found that the latter is more prone to efficiency losses at high photon flux [60].

The overall available catalytically active surface area in the system may also be increased by using a higher catalyst mass or concentration. The effects of doing so are superimposed by the altered photon absorption and reflection of more concentrated solutions so direct interpretation is difficult. However, it is often observed that the reaction rate improves with higher catalyst mass even after the point at which all photons are already absorbed. Furthermore, it could be shown recently in two reaction systems that increasing the photocatalyst concentration can counteract the efficiency losses at high light intensity to some degree $[39,40]$.

Higher surface area and catalyst mass also help to increase the overall substrate availability for the photogenerated charges. This can further be improved by higher substrate concentrations which generally also show a positive

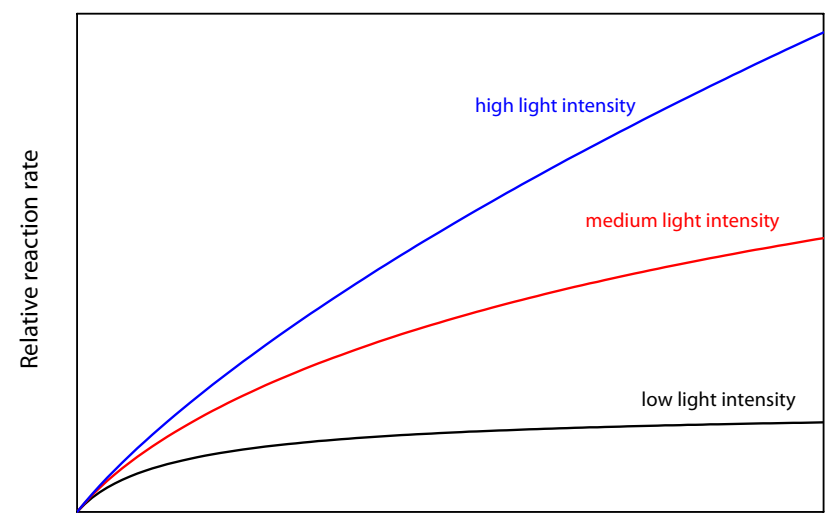

Available reactive surface area / a.u.

Fig. 4 Exemplary illustration of the reaction rate behavior with increased available reactive surface area (either by increased catalyst mass or specific surface area) for different light intensities effect up to a certain saturation point. This saturation point has also been shown to increase with higher light intensity, i.e., higher light intensity demands higher substrate concentrations to prevent limitations [34, 41, 61, 62].

In intensified systems, care also needs to be taken that the mass transfer is sufficiently high, i.e., that converted substrates at the photocatalyst surface are replaced fast enough. For instance, it could be shown that using a gas-permeable photocatalytic membrane can dramatically improve both the oxygen concentration and mass-transfer to the catalyst and thereby increase the oxygen reduction rate by the factor of more than 40 [63]. Interestingly, the advantage of this system was much more pronounced at higher light intensity, highlighting the higher mass-transfer demands of the intensified conditions [63].

\section{Improving the Catalyst Itself}

For kinetically challenging reactions such as hydrogen evolution it has long since been practice to employ so-called co-catalysts such as platinum [64]. In these systems, the photocatalyst material only serves to harvest the light energy and generate charge carriers. These are then transferred to the co-catalyst anchored at the surface, which then realizes the actual reaction. So in this case, the task of catalyzing the surface reaction is "outsourced" to another material, which can be designed with only the catalytic properties in mind without the constraints of also regarding the photophysical properties. This nicely circumvents the dilemma that good photoabsorbers are often bad catalysts and vice versa due to conflicting design criteria [64-66]. Using co-catalysts may also enable different product selectivity without affecting other properties of the photocatalyst.

Yet, there are many photocatalytic transformations being attempted with bare photocatalyst materials such as unmodified titania, particularly in water remediation and synthetic chemistry. Nonetheless, the reported efficiencies for those reactions are not particularly bad. However, as stated above, only at high reaction rates is high catalytic efficiency actually required. Or rather to view it the other way around, at low light intensity even bad catalysts are sufficient. Quite likely, the typically employed photocatalysts such as $\mathrm{TiO}_{2}$ are bad catalysts for many of the reactions they are applied in.

Even simple reactions such as alcohol oxidation may not be overly efficient on a non-modified oxide surface. This is often not apparent since the photogenerated chemical potential is so high that the thermodynamic driving force is sufficient nonetheless, i.e. catalytic inefficiency is just overcompensated by sheer excess energy. For instance, at $\mathrm{pH} 7$ the one-electron oxidation potential of methanol is $+1.2 \mathrm{~V}_{\mathrm{NHE}}$ while the two-electron oxidation (accessible 
with a suitable catalyst) is much easier to realize with a potential at $-0.1 \mathrm{~V}_{\mathrm{NHE}}$ [67]. However, this significant difference is overshadowed by the huge energy difference to the valence band edge of anatase $\mathrm{TiO}_{2}$ in either case $(+2.5$ $\mathrm{V}_{\mathrm{NHE}}$ ), which allows for $1.3 \mathrm{~V}$ of overpotential (equivalent to an excess energy of $125 \mathrm{~kJ} \mathrm{~mol}^{-1}$ ) even in case of the less favorable one-electron oxidation. Moreover, under conditions of low light intensity or rather low reaction rates the catalyst is not challenged, i.e. it is operated far below its maximum turnover frequency. Only intensified conditions can reveal how good or bad a given catalyst really is!

Co-catalysts have also been found to be particularly important when using larger particles materials with a low surface area [68]. This indicates that efficient surface catalysis can counteract the negative effects of smaller available surface area to some degree.

These co-catalysts can be deposited on the photocatalyst by impregnation, co-precipitation or by just mixing the two materials together. More elegant methods are grafting and photodeposition as these are more selective in creating the desired photocatalyst-cocatalyst interface. Grafting has for instance been done with many transition metal ions such as $\mathrm{Cu}$ (II) or $\mathrm{Fe}$ (III), taking advantage of their extensive redox chemistry [66, 69-74]. These ions are just adsorbed on the host material's surface as isolated single ions, small clusters or even monolayers [73-76]. Due to the typically high degree of dispersion, even very low amounts of these cocatalysts can make a dramatic difference. For instance, it was found that grafting P25 with just $0.04 \%$ of Fe(III) increased the gas phase $\mathrm{NO}_{2}$ oxidation rate by the factor of 9 [73]. This technique has the additional advantage that the co-catalyst may in some cases also be directly excited by interfacial charge transfer by visible light and thus bestow visible light activity upon the material $[66,70]$.

The photodeposition technique makes use of the photocatalyst's intrinsic ability to catalyse redox reactions. The photocatalyst is dispersed in a soluble co-catalyst precursor which is then under illumination selectively oxidized or reduced on the photocatalyst surface to a non-soluble form, precipitating directly on the surface. This technique is very popular for noble metal co-catalysts as the respective precursors such as hexachloroplatinate are very easy to reduce by the photocatalyst [77].

It is even possible to selectively deposit two different co-catalysts on different facets of a given crystal, creating specific separate zones on the particle for oxidation and reduction, respectively [78]. This is accomplished by small differences in the adsorption behavior or surface potential, which may lead to preferential deposition of catalysts on different surfaces. It is therefore particularly beneficial to utilize photodeposition techniques in this case to leverage natural gradients, i.e. deposit the co-catalysts specifically where the respective charges preferentially accumulate anyway [79]. It has also been suggested that very efficient redox catalysis at the photocatalyst surface may even create a gradient of electrochemical potential which facilitates effective charge separation inside the bulk of the photocatalyst [79]. Recently, it has been demonstrated that by using this methodology, quantum yields of almost unity are possible even for kinetically demanding reactions such as water splitting [80].

It should be noted that there are also other strategies to improve the catalytic efficiency of the employed photocatalysts. A commonly adapted strategy for example is heteroatom doping of the bulk photocatalyst material [81, 82]. This may alter the band positions and charge carrier density and thereby the redox potential. If a better match for the target reactions is achieved, this may also increase the charge-transfer efficiency. As a side-effect, usually some of the heteroatom dopants will statistically end up at the surface and may there also act as co-catalysts, adding to the abovementioned effect [83]. However, this method has the significant disadvantage, that the bulk doping may also change the photophysical properties of the material, so the catalytic properties cannot be manipulated independently.

If a given reaction is intensified using higher light intensity, the employed photocatalyst needs to be effective enough to handle the increased charge carrier flux. This will usually make the use of co-catalysts mandatory as the materials used as photocatalysts are not ideal catalysts for the majority of reactions.

\section{Conclusion}

Modern high-power LEDs and innovative photoreactor concepts nowadays enable heterogeneous photocatalytic reactions to theoretically be performed fast enough for industrial implementation in the synthesis of value-added chemicals. However, when performed under these conditions catalytic insufficiency will start to take effect, dramatically reducing the efficiency of the reaction.

If the amount of generated charges is increased by tuning the light intensity but mass transfer and catalysis remain unchanged, this causes a kinetic bottleneck at the particle surface which is the cause of the inefficiency at high light intensity. Consequently, when intensifying heterogeneous photocatalytic reactions mass transfer and catalysis need to be improved alongside with the increased light intensity! If this is done correctly, heterogeneous photocatalytic processes which are both highly efficient and fast are possible, facilitating their industrial implementation.

This can be realized by improving the catalytic properties of the employed materials, i.e. improving the rate of charge transfer from the photocatalyst to the target substrate. Strategies to achieve this are mostly akin to traditional thermal 
catalysis, e.g. using higher temperature or higher catalyst concentration and surface area. On the other hand, the photocatalysts themselves need to be looked at. They can be modified to feature co-catalysts which then take over the task of catalyzing the desired reaction.

Consequently, on the road to industrial implementation research will likely see a shift from the optimization of the photophysical properties of photoabsorber materials to optimizing their catalytic properties or co-catalysts. Reaction conditions will also be looked at in more detail, improving mass transfer, substrate availability and possibly moving to higher reaction temperatures.

Funding Open Access funding enabled and organized by Projekt DEAL.

\section{Declarations}

Conflict of interest The author declares no conflicts of interest.

Open Access This article is licensed under a Creative Commons Attribution 4.0 International License, which permits use, sharing, adaptation, distribution and reproduction in any medium or format, as long as you give appropriate credit to the original author(s) and the source, provide a link to the Creative Commons licence, and indicate if changes were made. The images or other third party material in this article are included in the article's Creative Commons licence, unless indicated otherwise in a credit line to the material. If material is not included in the article's Creative Commons licence and your intended use is not permitted by statutory regulation or exceeds the permitted use, you will need to obtain permission directly from the copyright holder. To view a copy of this licence, visit http://creativecommons.org/licenses/by/4.0/.

\section{References}

1. Fujishima A, Zhang X (2006) Titanium dioxide photocatalysis: present situation and future approaches. Comptes Rendus Chim 9(5-6):750-760. https://doi.org/10.1016/j.crci.2005.02.055

2. Zhang H, Chen G, Bahnemann DW (2009) Photoelectrocatalytic materials for environmental applications. J Mater Chem 19(29):5089. https://doi.org/10.1039/b821991e

3. Zhong L, Haghighat F (2015) Photocatalytic air cleaners and materials technologies-abilities and limitations. Build Environ 91:191-203. https://doi.org/10.1016/j.buildenv.2015.01.033

4. Fateh R, Ismail AA, Dillert R, Bahnemann DW (2011) Highly active crystalline mesoporous $\mathrm{TiO}_{2}$ films coated onto polycarbonate substrates for self-cleaning applications. J Phys Chem C 115(21):10405-10411. https://doi.org/10.1021/jp200892z

5. Tobaldi DM, Graziani L, Seabra MP, Hennetier L, Ferreira P, Quagliarini E, Labrincha JA (2017) Functionalised exposed building materials: self-cleaning photocatalytic and biofouling abilities. Ceram Int 43(13):10316-10325. https://doi.org/10.1016/j.ceram int.2017.05.061

6. Li K, Peng B, Peng T (2016) Recent advances in heterogeneous photocatalytic $\mathrm{CO}_{2}$ conversion to solar fuels. ACS Catal 6(11):7485-7527. https://doi.org/10.1021/acscatal.6b02089
7. Li J, Wu N (2015) Semiconductor-based photocatalysts and photoelectrochemical cells for solar fuel generation: a review. Catal Sci Technol 5(3):1360-1384. https://doi.org/10.1039/C4CY00974F

8. Ciriminna R, Delisi R, Xu YJ, Pagliaro M (2016) Toward the Waste-free synthesis of fine chemicals with visible light. Org Process Res Dev 20(2):403-408. https://doi.org/10.1021/acs. oprd.5b00424

9. Cherevatskaya M, König B (2014) Heterogeneous photocatalysts in organic synthesis. Russ Chem Rev 83(3):183-195. https://doi. org/10.1070/RC2014v083n03ABEH004427

10. Friedmann D, Hakki A, Kim H, Choi W, Bahnemann D (2016) Heterogeneous photocatalytic organic synthesis: state-of-the-art and future perspectives. Green Chem 18(20):5391-5411. https:// doi.org/10.1039/C6GC01582D

11. Cambié D, Bottecchia C, Straathof NJW, Hessel V, Noël T (2016) Applications of continuous-flow photochemistry in organic synthesis, material science, and water treatment. Chem Rev 116(17):10276-10341. https://doi.org/10.1021/acs.chemrev.5b007 07

12. Bloh JZ, Marschall R (2017) Heterogeneous photoredox catalysis: reactions, materials, and reaction engineering. Eur J Org Chem 2017(15):2085-2094. https://doi.org/10.1002/ejoc.20160 1591

13. Romero NA, Nicewicz DA (2016) Organic photoredox catalysis. Chem Rev 116(17):10075-10166. https://doi.org/10.1021/acs. chemrev.6b00057

14. Balzani V, Bergamini G, Ceroni P (2015) Light: a very peculiar reactant and product. Angew Chem Int Ed 54(39):11320-11337. https://doi.org/10.1002/anie.201502325

15. Ravelli D, Dondi D, Fagnoni M, Albini A (2009) Photocatalysis a multi-faceted concept for green chemistry. Chem Soc Rev 38(7):1999-2011. https://doi.org/10.1039/b714786b

16. Crisenza GEM, Melchiorre P (2020) Chemistry glows green with photoredox catalysis. Nat Commun 11(1):8-11. https://doi. org/10.1038/s41467-019-13887-8

17. Arias-Rotondo DM, McCusker JK (2016) The photophysics of photoredox catalysis: a roadmap for catalyst design. Chem Soc Rev 45(21):5803-5820. https://doi.org/10.1039/c6cs00526h

18. Harper KC, Moschetta EG, Bordawekar SV, Wittenberger SJ (2019) A laser driven flow chemistry platform for scaling photochemical reactions with visible light. ACS Cent Sci 5(1):109-115. https://doi.org/10.1021/acscentsci.8b00728

19. Le CC, Wismer MK, Shi Z-C, Zhang R, Conway DV, Li G, Vachal P, Davies IW, MacMillan DWC (2017) A general small-scale reactor to enable standardization and acceleration of photocatalytic reactions. ACS Cent Sci 3(6):647-653. https://doi.org/10.1021/ acscentsci.7b00159

20. Casado C, Timmers R, Sergejevs A, Clarke CT, Allsopp DWE, Bowen CR, van Grieken R, Marugán J (2017) Design and validation of a led-based high intensity photocatalytic reactor for quantifying activity measurements. Chem Eng J 327:1043-1055. https ://doi.org/10.1016/j.cej.2017.06.167

21. Matsushita Y, Ohba N, Kumada S, Sakeda K, Suzuki T, Ichimura T (2007) Photocatalytic reactions in microreactors. Chem Eng J 135:303-308. https://doi.org/10.1016/j.cej.2007.07.045

22. Gorges R, Meyer S, Kreisel G (2004) Photocatalysis in microreactors. J Photochem Photobiol A 167:95-99. https://doi. org/10.1016/j.jphotochem.2004.04.004

23. Straathof NJW, Su Y, Hessel V, Noël T (2016) Accelerated Gasliquid visible light photoredox catalysis with continuous-flow photochemical microreactors. Nat Protoc 11(1):10-21. https:// doi.org/10.1038/nprot.2015.113

24. Rehm TH, Gros S, Löb P, Renken A (2016) Photonic contacting of gas-liquid phases in a falling film microreactor for continuousflow photochemical catalysis with visible light. React Chem Eng 1(6):636-648. https://doi.org/10.1039/c6re00169f 
25. Rath T, Bloh JZ, Lüken A, Ollegott K, Muhler M (2020) Modelbased analysis of the photocatalytic $\mathrm{HCl}$ oxidation kinetics over $\mathrm{TiO}_{2}$. Ind Eng Chem Res 59(10):4265-4272. https://doi. org/10.1021/acs.iecr.9b05820

26. Wriedt B, Kowalczyk D, Ziegenbalg D (2018) Experimental determination of photon fluxes in multilayer capillary photoreactors. ChemPhotoChem 2(10):913-921. https://doi.org/10.1002/ cptc. 201800106

27. Van Gerven T, Mul G, Moulijn J, Stankiewicz A (2007) A review of intensification of photocatalytic processes. Chem Eng Process Process Intensif 46:781-789. https://doi.org/10.1016/j. cep.2007.05.012

28. Burek BO, Sutor A, Bahnemann DW, Bloh JZ (2017) Completely integrated wirelessly-powered photocatalyst-coated spheres as a novel means to perform heterogeneous photocatalytic reactions. Catal Sci Technol 7(21):4977-4983. https://doi.org/10.1039/ C7CY01537B

29. Herrmann J (1999) Heterogeneous photocatalysis: fundamentals and applications to the removal of various types of aqueous pollutants. Catal Today 53(1):115-129. https://doi.org/10.1016/S0920 $-5861(99) 00107-8$

30. Dilla M, Mateblowski A, Ristig S, Strunk J (2017) Photocatalytic $\mathrm{CO}_{2}$ reduction under continuous flow high-purity conditions: influence of light intensity and $\mathrm{H}_{2} \mathrm{O}$ concentration. ChemCatChem 9(23):4345-4352. https://doi.org/10.1002/cctc.201701189

31. Herrmann J-M (2005) Heterogeneous photocatalysis: state of the art and present applications. Top Catal 34(1-4):49-65. https://doi. org/10.1007/s11244-005-3788-2

32. Dillert R, Stötzner J, Engel A, Bahnemann DW (2012) Influence of inlet concentration and light intensity on the photocatalytic oxidation of nitrogen(ii) oxide at the surface of aeroxide ${ }^{\circledR} \mathrm{TiO}_{2}$ P25. J Hazard Mater 211-212:240-246. https://doi.org/10.1016/j. jhazmat.2011.11.041

33. Takeuchi S, Takashima M, Takase M, Ohtani B (2018) Digitally controlled kinetics of titania-photocatalyzed oxygen evolution. Chem Lett 47(3):373-376. https://doi.org/10.1246/cl.171093

34. Emeline AV, Rudakova AV, Ryabchuk VK, Serpone N (1998) Photostimulated reactions at the surface of wide band-gap metal Oxides $\left(\mathrm{ZrO}_{2}\right.$ And $\left.\mathrm{TiO}_{2}\right)$ : interdependence of rates of reactions on pressure-concentration and on light intensity. J Phys Chem B 102(52):10906-10916. https://doi.org/10.1021/jp9830373

35. Ohtani B (2010) Photocatalysis a to $\mathrm{z}$-what we know and what we do not know in a scientific sense. J Photochem Photobiol C 11(4):157-178. https://doi.org/10.1016/j.jphotochem rev.2011.02.001

36. Ohtani B (2013) Titania photocatalysis beyond recombination: a critical review. Catalysts 3(4):942-953. https://doi.org/10.3390/ catal3040942

37. Choi W, Termin A, Hoffmann MR (1994) The role of metal ion dopants in quantum-sized $\mathrm{tio}_{2}$ : correlation between photoreactivity and charge carrier recombination dynamics. J Phys Chem 98:13669-13679

38. Marschall R (2014) Semiconductor composites: strategies for enhancing charge carrier separation to improve photocatalytic activity. Adv Funct Mater 24(17):2421-2440. https://doi. org/10.1002/adfm.201303214

39. Patzsch J, Berg B, Bloh JZ (2019) Kinetics and optimization of the photocatalytic reduction of nitrobenzene. Front Chem 7:289-298. https://doi.org/10.3389/fchem.2019.00289

40. Burek BO, Bahnemann DW, Bloh JZ (2019) Modeling and optimization of the photocatalytic reduction of molecular oxygen to hydrogen peroxide over titanium dioxide. ACS Catal 9(1):25-37. https://doi.org/10.1021/acscatal.8b03638

41. Bloh JZ (2019) A holistic approach to model the kinetics of photocatalytic reactions. Front Chem 7:128-140. https://doi. org/10.3389/fchem.2019.00128
42. Malato S, Fernández-Ibáñez P, Maldonado MI, Blanco J, Gernjak W (2009) Decontamination and disinfection of water by solar photocatalysis: recent overview and trends. Catal Today 147(1):1-59. https://doi.org/10.1016/j.cattod.2009.06.018

43. Gaya U, Abdullah A (2008) Heterogeneous photocatalytic degradation of organic contaminants over titanium dioxide: a review of fundamentals, progress and problems. J Photochem Photobiol C 9(1):1-12. https://doi.org/10.1016/j.jphotochemrev.2007.12.003

44. Carp O, Huisman CL, Reller A (2004) Photoinduced reactivity of titanium dioxide. Prog Solid State Chem 32(1-2):33-177. https:// doi.org/10.1016/j.progsolidstchem.2004.08.001

45. Al-Sayyed G, D’Oliveira JC, Pichat P (1991) Semiconductorsensitized photodegradation of 4-chlorophenol in water. J Photochem Photobiol A 58(1):99-114. https://doi.org/10.1016/10106030(91)87101-Z

46. Soares ET, Lansarin MA, Moro CC (2007) A study of process variables for the photocatalytic degradation of rhodamine B. Braz J Chem Eng 24(1):29-36. https://doi.org/10.1590/S0104-66322 007000100003

47. Hu Q, Liu B, Zhang Z, Song M, Zhao X (2010) Temperature effect on the photocatalytic degradation of methyl orange under UV-vis light irradiation. J Wuhan Univ Technol Sci Ed 25(2):210-213. https://doi.org/10.1007/s11595-010-2210-5

48. Costacurta S, Maso GD, Gallo R, Guglielmi M, Brusatin G, Falcaro P (2010) Influence of temperature on the photocatalytic activity of sol-gel $\mathrm{TiO}_{2}$ films. ACS Appl Mater Interfaces 2(5):1294-1298. https://doi.org/10.1021/am100149e

49. Hirakawa T, Whitesell JK, Fox MA (2004) Effect of temperature and pressure in the photocatalytic oxidation of $n$-octanol on partially desilanized hydrophobic $\mathrm{TiO}_{2}$ suspended in aerated supercritical $\mathrm{CO}_{2}$. J Phys Chem B 108(29):10213-10218. https ://doi.org/10.1021/jp0364957

50. Westrich TA, Dahlberg KA, Kaviany M, Schwank JW (2011) High-temperature photocatalytic ethylene oxidation over $\mathrm{TiO}_{2}$. J Phys Chem C 115(33):16537-16543. https://doi.org/10.1021/ jp204405h

51. Li Y, Peng Y-K, Hu L, Zheng J, Prabhakaran D, Wu S, Puchtler TJ, Li M, Wong K-Y, Taylor RA, Tsang SCE (2019) Photocatalytic water splitting by $\mathrm{N}-\mathrm{TiO}_{2}$ on $\mathrm{MgO}$ (111) with exceptional quantum efficiencies at elevated temperatures. Nat Commun 10(1):4421-4429. https://doi.org/10.1038/s41467-019-12385-1

52. Rath T, Uhrich A, Lüken A, Zhao G, Rittermeier A, Muhler $\mathrm{M}$ (2019) $\mathrm{Cl}_{2}$ production by photocatalytic oxidation of $\mathrm{HCl}$ over $\mathrm{TiO}_{2}$. Chemsuschem 12(12):2725-2731. https://doi. org/10.1002/cssc. 201900642

53. Wang Y, Arandiyan H, Scott J, Bagheri A, Dai H, Amal R (2017) Recent advances in ordered meso/macroporous metal oxides for heterogeneous catalysis: a review. J Mater Chem A 5(19):8825-8846. https://doi.org/10.1039/c6ta10896b

54. Vorontsov AV, Kabachkov EN, Balikhin IL, Kurkin EN, Troitskii VN, Smirniotis PG (2018) Correlation of surface area with photocatalytic activity of $\mathrm{TiO}_{2}$. J Adv Oxid Technol 21(1):127137. https://doi.org/10.26802/jaots.2017.0063

55. Wilmer H, Kurtz M, Klementiev KV, Tkachenko OP, Grünert W, Hinrichsen O, Birkner A, Rabe S, Merz K, Driess M, Wöll C, Muhler M (2003) methanol synthesis over $\mathrm{ZnO}$ : a structuresensitive reaction? Phys Chem Chem Phys 5(20):4736-4742. https://doi.org/10.1039/b304425d

56. Cabrera MI, Alfano OM, Cassano AE (1996) Absorption and scattering coefficients of titanium dioxide particulate suspensions in water. J Phys Chem 100(51):20043-20050. https://doi. org/10.1021/jp962095q

57. Amano F, Nogami K, Tanaka M, Ohtani B (2010) Correlation between surface area and photocatalytic activity for acetaldehyde decomposition over bismuth tungstate particles with a 
hierarchical structure. Langmuir 26(10):7174-7180. https:// doi.org/10.1021/1a904274c

58. Cheng H, Wang J, Zhao Y, Han X (2014) Effect of Phase composition, morphology, and specific surface area on the photocatalytic activity of $\mathrm{TiO}_{2}$ nanomaterials. RSC Adv 4(87):4703147038. https://doi.org/10.1039/c4ra05509h

59. Lukic S, Menze J, Weide P, Busser GW, Winterer M, Muhler M (2017) Decoupling the effects of high crystallinity and surface area on the photocatalytic overall water splitting over B-Ga2O3 nanoparticles by chemical vapor synthesis. Chemsuschem 10(21):4190-4197. https://doi.org/10.1002/cssc.20170 1309

60. Megatif L, Dillert R, Bahnemann DW (2020) Determination of the quantum yield of a heterogeneous photocatalytic reaction employing a black body photoreactor. Catal Today 355:698-703. https:// doi.org/10.1016/j.cattod.2019.06.008

61. Emeline AV, Ryabchuk V, Serpone N (2000) Factors affecting the efficiency of a photocatalyzed process in aqueous metal-oxide dispersions. J Photochem Photobiol A 133(1-2):89-97. https:// doi.org/10.1016/S1010-6030(00)00225-2

62. Ollis DF (2005) Kinetics of liquid phase photocatalyzed reactions: an illuminating approach. J Phys Chem B 109(6):2439-2444. https://doi.org/10.1021/jp040236f

63. Liu Z, Sheng X, Wang D, Feng X (2019) Efficient hydrogen peroxide generation utilizing photocatalytic oxygen reduction at a triphase interface. iScience 17:67-73. https://doi.org/10.1016/j. isci.2019.06.023

64. Yang J, Wang D, Han H, Li C (2013) Roles of cocatalysts in photocatalysis and photoelectrocatalysis. Acc Chem Res 46(8):19001909. https://doi.org/10.1021/ar300227e

65. Busser GW, Mei B, Pougin A, Strunk J, Gutkowski R, Schuhmann W, Willinger MG, Schlögl R, Muhler M (2014) Photodeposition of copper and chromia on gallium oxide: the role of co-catalysts in photocatalytic water splitting. Chemsuschem 7(3):1030-1034. https://doi.org/10.1002/cssc.201301065

66. Neubert S, Pulisova P, Wiktor C, Weide P, Mei B, Guschin DA, Fischer RA, Muhler M, Beranek R (2014) Enhanced photocatalytic degradation rates at rutile $\mathrm{TiO}_{2}$ photocatalysts modified with redox co-catalysts. Catal Today 230:97-103. https://doi. org/10.1016/j.cattod.2013.11.046

67. Koppenol WH, Rush JD (1987) reduction potential of the CO2/ $\mathrm{CO} 2 *_{-}$\} couple: a comparison with other $\mathrm{C} 1$ radicals. J Phys Chem 91:4429-4430

68. Gerischer H, Heller A (1992) Photocatalytic oxidation of organic molecules at $\mathrm{tio}_{2}$ particles by sunlight in aerated water. J Electrochem Soc 139(1):113-118. https://doi.org/10.1149/1.2069154

69. Liu M, Qiu X, Miyauchi M, Hashimoto K (2013) Energylevel matching of fe(iii) ions grafted at surface and doped in bulk for efficient visible-light photocatalysts. J Am Chem Soc 135(27):10064-10072. https://doi.org/10.1021/ja401541k

70. Yu H, Irie H, Shimodaira Y, Hosogi Y, Kuroda Y, Miyauchi M, Hashimoto K (2010) An efficient visible-light-sensitive Fe(III)grafted $\mathrm{TiO}_{2}$ photocatalyst. J Phys Chem C 114(39):16481-16487. https://doi.org/10.1021/jp1071956

71. Kamiya K, Miura S, Hashimoto K, Irie H (2011) Photocatalytic and electrochemical characterizations of $\mathrm{Cu}(\mathrm{II})$-grafted $\mathrm{TiO}_{2}$. Electrochemistry 79(10):793-796. https://doi.org/10.5796/elect rochemistry. 79.793
72. Chu S, Becerikli AE, Kortewille B, Oropeza FE, Strunk J (2014) Tin-grafted $\mathrm{TiO}_{2}$ with enhanced activity for photocatalytic hydrogen generation from aqueous methanol solutions. Int J Hydrogen Energy 39(33):18784-18792. https://doi.org/10.1016/j.ijhyd ene.2014.09.103

73. Patzsch J, Spencer JN, Folli A, Bloh JZ (2018) Grafted Iron(III) ions significantly enhance $\mathrm{NO}_{2}$ oxidation rate and selectivity of $\mathrm{TiO}_{2}$ for photocatalytic NOx abatement. RSC Adv 8(49):2767427685. https://doi.org/10.1039/C8RA05017A

74. Neubert S, Mitoraj D, Shevlin SA, Pulisova P, Heimann M, Du Y, Goh GKL, Pacia M, Kruczała K, Turner S, Macyk W, Guo ZX, Hocking RK, Beranek R (2016) Highly efficient rutile $\mathrm{TiO}_{2}$ photocatalysts with single $\mathrm{Cu}(\mathrm{II})$ and $\mathrm{Fe}(\mathrm{III})$ surface catalytic sites. J Mater Chem A 4(8):3127-3138. https://doi.org/10.1039/C5TA0 $7036 \mathrm{H}$

75. Wachs IE (2005) Recent conceptual advances in the catalysis science of mixed metal oxide catalytic materials. Catal Today 100(1-2):79-94. https://doi.org/10.1016/j.cattod.2004.12.019

76. Jin Q, Fujishima M, Iwaszuk A, Nolan M, Tada H (2013) Loading effect in copper(ii) oxide cluster-surface-modified titanium(iv) oxide on visible- and UV-light activities. J Phys Chem C 117(45):23848-23857. https://doi.org/10.1021/jp4085525

77. Wenderich K, Mul G (2016) Methods, mechanism, and applications of photodeposition in photocatalysis: a review. Chem Rev 116(23):14587-14619. https://doi.org/10.1021/acs.chemrev.6b003 27

78. Li R, Zhang F, Wang D, Yang J, Li M, Zhu J, Zhou X, Han H, Li C (2013) Spatial separation of photogenerated electrons and holes among 010 and 110 crystal facets of BiVO4. Nat Commun 4:1432. https://doi.org/10.1038/ncomms2401

79. Adler C, Mitoraj D, Krivtsov I, Beranek R (2020) On the importance of catalysis in photocatalysis: triggering of photocatalysis at well-defined anatase $\mathrm{TiO}_{2}$ crystals through facet-specific deposition of oxygen reduction cocatalyst. J Chem Phys 152(24):244702. https://doi.org/10.1063/5.0013115

80. Takata T, Jiang J, Sakata Y, Nakabayashi M, Shibata N, Nandal V, Seki K, Hisatomi T, Domen K (2020) Photocatalytic water splitting with a quantum efficiency of almost unity. Nature 581(7809):411-414. https://doi.org/10.1038/s41586-020-2278-9

81. Khaki MRD, Shafeeyan MS, Raman AAA, Daud WMAW (2017) Application of doped photocatalysts for organic pollutant degradation-a review. J Environ Manage 198:78-94. https://doi. org/10.1016/j.jenvman.2017.04.099

82. Kumaravel V, Mathew S, Bartlett J, Pillai SC (2019) Photocatalytic hydrogen production using metal doped $\mathrm{TiO}_{2}$ : a review of recent advances. Appl Catal B 244:1021-1064. https://doi. org/10.1016/j.apcatb.2018.11.080

83. Bloh JZ (2017) Refined model for the optimal metal content in semiconductor photocatalysts. J Phys Chem C 121(1):844-851. https://doi.org/10.1021/acs.jpcc.6b09808

Publisher's Note Springer Nature remains neutral with regard to jurisdictional claims in published maps and institutional affiliations. 